\title{
REVIEW \\ INFLUENCE OF THE ROASTING PROCESS ON BIOACTIVE COMPOUNDS AND AROMA PROFILE IN SPECIALTY COFFEE: A REVIEW
}

\author{
Ilze Laukaleja*, Zanda Kruma, \\ Department of Food Technology, Faculty of Food Technology, Latvia University of Life Sciences and Technologies, \\ Rigas iela 22, Jelgava, Latvia, e-mail: ilze.laukaleja@gmail.com
}

\begin{abstract}
The coffee roasting process is one of the most important parts of coffee aroma formation, and also has a varied influence on the biologically active compounds composition in coffee. It is essential to understand the point of the roasting process when the pleasant specialty coffee aroma compounds and health-beneficial bioactive compounds are at the best ratio. The aim of the review was to evaluate the technological parameters in the specialty coffees roasting process to obtain optimal aroma profile and composition of bioactive compounds. The loss of aroma compounds with fruity, floral and sweet acidic notes in roasting process happens slower than the loss of chlorogenic acid. Meanwhile compounds like melanoidins with anti-oxidative properties and chlorogenic acid lactones mostly form in medium roasting level, but due to their bitter sensory characteristics, they have low cupping score. Both, the aroma compounds and bioactive compounds start rapidly decreasing by the medium-dark roast. It is proven, that antioxidant activity stays at the highest point in the light-medium roast level when coffee melanoidins start to form and the chlorogenic acid is still at high concentration and good cup quality remains. By knowing the roasting process influence on chemical properties of coffees aroma and bioactive compound composition it is possible to maintain high coffee cupping score without losing the valuable bioactive compounds.
\end{abstract}

Keywords: specialty coffee, roasting, aroma, phenolic compounds

\section{Introduction}

Moderate coffee consumption is more associated with positive health benefits. The bioactive compounds are responsible for the antioxidant, antibacterial and antiinflammatory activities. Their wide and powerful variety contributes to regular coffee consumption benefits. Moderate coffee consumption is associated with lower cardiovascular diseases risk, for example, Martínez-Lopez et al. (2018) research suggests that drinking 3 cups of coffee a day positively affects blood pressure, blood glucose and triglyceride levels, which overall contributes to lower metabolic syndrome risk. According to Gutiérrez-Grobe et al. (2012), higher coffee consumption is associated with lower nonalcoholic fatty liver disease risk. To better understand the antioxidant properties of coffee it is important to evaluate the bioactive compounds individually. Chlorogenic acid has shown the highest antioxidant activity in coffee. Chlorogenic acid can decrease breast and pancreatic cancer risk, as also empowering overall cardiovascular health (Keefe et al., 2013). Aside from the strong bitter flavour, phenylindanes are known with their neuroprotective effect in Alzheimer's disease pathologies (Mancini et al., 2018). Caffeine is one of the most powerful bioactive compounds in coffee. By drinking 3-5 cups of coffee a day it can prevent dementia risk in future (Carman et al., 2014). Also, caffeine has proven antidiabetic properties, caffeine has the ability to increase fat metabolism and control blood sugar level (Nuhu, 2014). Both, trigonelline and nicotinic acid show antioxidant properties to pancreatic cancer cells and trigonelline has ability to reduce blood glucose levels (Yoshinari, Igarashi, 2010). Melanoidins have powerful antibacterial activity against Grampositive (Staphylococcus aureus) and Gram-negative
(Escherichia coli, Salmonella typhimurium) bacteria (Moreira et al., 2012). Also, melanoidins can act as dietary fibre (Carman et al., 2014), this could approve the positive influence of melanoidins on healthy gut microbiota (Lopes et al., 2016; Coelho, 2014). All bioactive compounds from sensory point of view have bitter flavour notes, which can influence the overall coffee taste.

Specialty coffee is coffee which is standardized by the whole coffee process cycle from choosing coffee plantation criteria's till coffee brew serving to client. Specialty coffee flavour is focused on more fruity, floral and acidic notes. The presence of at least five different flavour notes within balance in coffee is valued with higher sensory score (McCoy et al., 2017; Alex et al., 2016). The sensory analysis system for specialty coffee is cup tasting or cupping, which is done by Specialty Coffee Association (SCA) guidelines and cupping protocol (2015).

The roasting process is responsible for cascade chemical reactions, in which from non-volatile compound degradation forms new compounds with potential flavour attributes (Toledo et al., 2016).

Despite the fact that the roasting process is widely analysed it is challenging to compare the roasting levels between studies because the roasting parameters are significantly different (Table 1). Several studies only indicate roasting level without specific time and temperature parameters. In previous studies the roasting temperature for specialty coffee was mostly chosen in range between $160-200{ }^{\circ} \mathrm{C}$ and roasting time range between 4-12 minutes (Fassio et al., 2017; Tolessa et al., 2016; Piccino et al., 2014). From specialty coffee point of view, Moon, Shibamoto, (2009) research have the most similar roasting parameters with roasting 
standards in Latvia specialty coffee roasteries, these parameters were chosen as roast level measures in this review.

Main chemical reactions during roasting are Maillard reaction, Strecker degradation. Non-volatile compounds involved in Maillard reaction are amino acids and reducing sugars forming end products melanoidins during roasting (Vignoli et al., 2014). Chlorogenic acid degradation is also involved in melanoidin formation and passes the antioxidant activity (Bartel et al., 2015). Strecker degradation is responsible for free amino acid reactions in roasting process, creating beneficial flavour compounds. One of Strecker compounds are 2,3-pentanedione with buttery flavour notes, methanethiol with fresh, airy flavour notes (Kim et al., 2018; Cheong et al., 2013).

Table 1

Coffee roasting parameters

\begin{tabular}{lccc}
\hline \multirow{2}{*}{ References } & \multicolumn{3}{c}{ Roasting level } \\
\cline { 2 - 4 } & Light & Medium & Dark \\
\hline Moon, & $170-230$ & $230-240$ & $240-250$ \\
Shibamoto & ${ }^{\circ} \mathrm{C}$ & ${ }^{\circ} \mathrm{C}$ & ${ }^{\circ} \mathrm{C}$ \\
(2009) & & & \\
Bhumiratana & $180-205{ }^{\circ} \mathrm{C}$ & $180-238{ }^{\circ} \mathrm{C}$ & $180-238{ }^{\circ} \mathrm{C}$ \\
et al. (2011) & $6 \operatorname{min~} 30 \mathrm{~s}$ & $7 \operatorname{min~} 30 \mathrm{~s}$ & $8 \operatorname{min~} 30 \mathrm{~s}$ \\
Somporn et & $230{ }^{\circ} \mathrm{C}$ & $240{ }^{\circ} \mathrm{C}$ & $250{ }^{\circ} \mathrm{C}$ \\
al. (2011) & $12 \mathrm{~min}$ & $14 \mathrm{~min}$ & $17 \mathrm{~min}$ \\
Vignoli et al. & $215^{\circ} \mathrm{C}$ & & $225^{\circ} \mathrm{C}$ \\
(2014) & $7 \mathrm{~min}$ & & $10 \mathrm{~min}$ \\
\hline
\end{tabular}

In the process of roasting, various compounds, that differ in structure and chemical properties, are formed, because of that, roasting parameters are very crucial in creating specific coffee flavours and overall quality (Vignoli et al., 2014). By understanding the roasting process effects on bioactive compound composition and aroma profile development, it could be possible to suggest guideline criteria to achieve high quality coffee with high beneficial bioactive compound content. The aim of the review was to evaluate the technological parameters in the specialty coffees roasting process to obtain optimal aroma profile and composition of bioactive compounds.

\section{Materials and Methods}

The study was preceded by using the monographic method and summarizing actual researches of influence of roasting process on individual bioactive compounds and aroma profile. The review summarises and evaluates the bioactive compound and aroma compound changes during roasting process.

\section{Results and Discussion}

Bioactive compounds change during the roasting process

Roasting process significantly decreases the concentration and therefore antioxidant ability of such biologically active compound as chlorogenic acid. Mojica et al. (2018) evaluated anticancer activities of coffee samples with different roast levels and in the result at light roast level $\left(225^{\circ} \mathrm{C}\right)$ coffee extracts had the highest total phenolic content and antioxidant capacity. Chlorogenic acid concentration decreased rapidly after roasting process, but gallic and caffeic acids had the highest concentration in light level roasted coffee $\left(225^{\circ} \mathrm{C}\right)$. The light roasted coffee extracts also showed the highest antiproliferative effect on colon cancer cells (Mojica et al., 2018). Other studies show that light roasted coffee can even increase antioxidant activity of melanoidins (Bekedam et al., 2008). But overall total polyphenol concentration is rapidly decreasing during roasting process. Several studies show that chlorogenic acid isomer 5-caffeoylquinic acid has the most significant concentration reduction: Duarte et al. (2005) study confirms that from green coffee to light roasted coffee 5-caffeoylquinic acid concentration decreases three times, but Vignoli et al. (2014) shows that 5-caffeoylquinic acid concentration decreases twice during the time from green to light roasted and three times from light roasted to medium roasted coffee (Jeszka-Skowron et al., 2016). While the 5-caffeoylquinic acid concentration is decreasing, the 4-caffeoylquinic acid and 3-caffeoylquinic acid concentration is increased from light to medium roast and only then the concentration is decreasing. By the degradation of chlorogenic acid chlorogenic acid lactones are formed, most common are 3-caffeoylquinic-1,5-lactone and 4-caffeoylquinic-1,5lactone forms. The highest chlorogenic acid and chlorogenic acid lactones concentration is found in light roast level (203 ${ }^{\circ} \mathrm{C}$ for $7 \mathrm{~min}$ ) coffee (Farah et al., 2005). From sensory point of view chlorogenic acid and chlorogenic acid lactones have light coffee-like bitterness. If the roasting process goes further than medium roast level, phenylindanes are formed with harsh bitterness and are one of the main bitter compounds in dark roasted coffees (Frank et al., 2007). While polyphenol concentration decreases in roasting process, the concentration of other bioactive compounds as melanoidins is increasing till medium-dark level roast (Coelho et al., 2014). In melanoidin formation polysaccharides, proteins and also phenolic compound like chlorogenic acid are involved. It is the reason why chlorogenic acid concentration has an opposite correlation between roasting level and melanoidin content (Moreira et al., 2012). It also suggests that higher roasting temperature helps the melanoidin compound formation from chlorogenic acid. Coffees roasted at $220{ }^{\circ} \mathrm{C}$ temperature had higher antioxidant concentration than coffees roasted at $217^{\circ} \mathrm{C}$, but at the same time coffees roasted above $228{ }^{\circ} \mathrm{C}$ lose their antioxidant activity (Pilipczuk, Kusznierewicz, 2014). Similar conclusions were stated in Bekedam et al. (2008) research, suggesting, that light roast level helps form melanoidins from chlorogenic acid, which also gives the antioxidant activity and characteristics. The given statement is approved by Coelho et al. (2014) and Vignoli et al. (2014) research results, that at the beginning of coffee melanoidin formation at light roast 
level, the chlorogenic acid content is still high and gives higher total antioxidant activity to coffee. It also slows down the more bitter phenolic compound formation (Farah et al., 2005). From cup quality point of view, melanoidins have important role in coffee crema formation and also bringing bittersweet flavour notes to coffee brew (Kim et al., 2018; Coelho et al., 2014).

During the roasting process, trigonelline converts to nicotinic acid. In Taguchi et al. (1985) research trigonelline concentration decreased rapidly with the roasting time. Meanwhile, nicotinic acid in the roasting process started to form at $180{ }^{\circ} \mathrm{C}$ temperature and after $20 \mathrm{~min}$ roasting at $220^{\circ} \mathrm{C}$ reached the highest concentration. Taguchi et al. (1985) suggests that trigonelline concentration is the highest in light roasted coffees (roasting temperature below $180{ }^{\circ} \mathrm{C}$ and roasting time is no longer than 10 minutes). Trigonelline is important precursor of volatile compounds and from sensory point of view higher trigonelline concentration is associated with better sensory scores. Fassio et al. (2017) research shows that trigonelline content in coffee brew has positive correlation with sucrose content and cup quality, while chlorogenic acid has negative correlation.

Kahweol and cafestol concentration decreases significantly after 8 minute roasting time at $230{ }^{\circ} \mathrm{C}$, and dehydro derivatives are formed. Kahweol and cafestol stability in roasting process depends on roasting temperature - if the temperature is below $230{ }^{\circ} \mathrm{C}$ reduction of these compounds is slower (Carlos et al., 2014).

For maintaining beneficial bioactive compound content in roasted coffee, the medium roast level is the most appropriate. At this roast level from temperature point of view coffee roasted in the range between 200 to $225^{\circ} \mathrm{C}$ could have the highest composed content of trigonelline, chlorogenic acid, kahweol and cafestol content and also presence of melanoidin and chlorogenic acid lactones could be possible.

\section{Aroma and flavour compound changes during roasting process}

The roasting process significantly influences the chemical composition of coffee beans. Light or lightmedium roasted coffees are more intense with the fruity, acidic and citrusy notes. Although in light roast coffees, there is a higher chance to detected green coffee bean defects (physiological and microbiological defects). Meanwhile, dark roasted coffees have lost the pleasant aroma, flavour compounds and are focused on high concentrations of coffee-like, roasted and burned notes (Parenti et al., 2014; Steen et al., 2017). In Table 2 is shown odour and roast level description of roasted coffee brew compounds. The roast level parameters used in Table 1 are according to Moon, Shibamoto (2009) research.

The presence of a higher content of phenolic compounds, for example, 2-methylphenol, 4-vinylguaiacol, in roasted coffee is associated with immature bean defects (coffee cherries picked before ripeness or affected with rust disease), but by adjusting roasting process it is possible to reduce the concentrations of these compound (Craig, 2018; Steen, 2017). With increasing roasting time 5 -feruloylquinic acid hydrolyzes to form ferulic acid, and the ferulic acid decarboxylates to 4-vinylguaiacol (spicy, smoky flavour), but this formation process can happen if the roasting temperature is kept below $170{ }^{\circ} \mathrm{C}$ (Dorfner et al., 2003). To avoid the unpleasant flavour notes, at this point it is important to increase roast temperature above $170{ }^{\circ} \mathrm{C}$ (Wei et al., 2017).

Aroma, flavour compound description

Table 2

\begin{tabular}{|c|c|c|}
\hline Compound & Odour & $\begin{array}{c}\text { Roast level with } \\
\text { the highest } \\
\text { concentration }\end{array}$ \\
\hline \multicolumn{3}{|c|}{ positive effect on cup quality* } \\
\hline (E)- $\beta$-damascenone & $\begin{array}{l}\text { cooked } \\
\text { apple, } \\
\text { sweet }^{\text {a }}\end{array}$ & light \\
\hline 3-methylbutanal & malt $^{\mathrm{b}}$ & medium \\
\hline 2-phenylacetaldehyde & floral, fruit ${ }^{\mathrm{c}}$ & light \\
\hline hydroxymethylfurfural & honey $^{\mathrm{d}}$ & light \\
\hline 2-methylpyrazine & $\begin{array}{l}\text { chocolate, } \\
\text { nutty }\end{array}$ & light \\
\hline 2-pentanone & $\begin{array}{l}\text { sweet, } \\
\text { fruity }^{f}\end{array}$ & light \\
\hline 2,3-butanedione & buttery ${ }^{\mathrm{f}}$ & medium \\
\hline methanethiol & fresh $^{\mathrm{g}}$ & medium \\
\hline \multicolumn{3}{|c|}{ negative effect on cup quality* } \\
\hline dimethyl disulphide & sulphury $^{\mathrm{g}}$ & dark \\
\hline 2- methyl-3-furanthiol & $\begin{array}{l}\text { sulphury, } \\
\text { vegetable } \\
\text { flavour }^{b}\end{array}$ & dark \\
\hline 2-methylpyrazine & $\begin{array}{l}\text { overripe, } \\
\text { harsh }^{\mathrm{g}}\end{array}$ & dark \\
\hline 4-vinylguaiacol & smoky $^{\mathrm{h}}$ & $\begin{array}{l}\text { light (low } \\
\text { temperature) }\end{array}$ \\
\hline
\end{tabular}

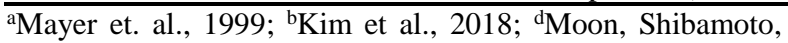
2009; 'Wei et al., 2017; ' Toledo et al., 2016; ' $P$ Poltronieri, Rossi, 2016; ' ${ }^{\mathrm{g}}$ Yang et al., 2016; ${ }^{\mathrm{h}}$ Dorfner et al., 2003

*Cup quality term for sensory evaluation of coffee brew (flavour, aroma, texture) (Cheong et al., 2013; Donnet et al., 2008; Suslick et al., 2010).

Strecker aldehydes like 2-methylpropanal and 3-methylbutanal are responsible for malt flavour notes in coffee (Kim et al., 2018). Also as positive indicators of coffee quality after roasting is 3-metilbutanal and 2,3-pentanedione (Toledo et al., 2016; Ribeiro et al., 2010). Piccino et al. (2014) highlight 2-phenylacetaldehyde and hexanal as compounds with a pleasant specialty coffee like flavours (sweet fruits, citrus or green vegetables). These compounds are in high concentration in green coffee beans and remain only after light roast level (roasting temperature $210^{\circ} \mathrm{C}$ for $4-5$ minutes) (Kim et al., 2018; Piccino et al., 2014).

Ketones like 2,3-butanedione and 2,3-pentanedione are responsible for buttery flavour notes and their highest concentration is at medium roast level. Sweet and fruity 
flavour notes in coffee are associated with the presence of compounds such as 2-pentanone (Toledo et al., 2016) and (E)- $\beta$-damascenone (pleasant cooked apple, fruity, tea flavour notes), but their concentration rapidly decreases after light roast level (Mayer et al., 1999). Ketones and aldehydes are good cup quality markers, because of the sensibility to changes, especially in roasting process (Poltronieri, Rossi, 2016).

Furans are responsible for coffee-like, caramel flavour notes in light roasted coffees, but with increasing roast level the bitter, spicy furan flavour compounds are developed. Furfural is associated with coffee-like, fresh bread notes and has the highest concentration in light roasted coffee (Cheong et al., 2013; Somporn et al., 2011). Similar to trigonelline, furfural concentration is the highest at light roast level if roasting temperature balance at $200{ }^{\circ} \mathrm{C}$. Hydroxymethylfurfural (honey flavour notes) concentration is the highest in light roasted coffee at roasting temperature $230{ }^{\circ} \mathrm{C}$ for 12 minutes (Vignoli et al., 2014; Moon, Shibamoto, 2009). Murkovic, Bornik (2007) research shows, that by increasing roasting temperature to $240{ }^{\circ} \mathrm{C}$ hydroxymethylfurfural reaches the highest concentration in 3 minutes, and afterwards the concentration rapidly decreases. Furanones have similar characteristics. For example, furaneol is associated with sweet caramel, but only in light roasted coffees (Bressanello et al., 2017; Cheong et al., 2013).

Pyrazine compounds can bring both negative and positive flavour aroma variations in coffee. Pyrazine like 2-methylpyrazine (chocolate, nutty flavour notes) and 2-ethyl-6-methylpyrazine (roasted hazelnut flavour notes) have positive flavour notes if the roast level is light (Wei et al., 2017), because in dark roasted coffees 2-methylpyrazine and 2-ethyl-6-methylpyrazine associates with "black roast defect" (overripe, harsh, fermented) flavour (Yang et al., 2016). Velásquez et al. (2019) research confirms, that immature coffee beans after roasting at light roast level have a higher concentration of volatile phenols and pyrazines with an earthy odour, meanwhile having lower concentration of carbohydrate degradation products (caramel, sweet flavour notes) and worse sensory score. In this conclusion, specialty coffee eliminates the immature and overripe green coffee bean factor.

Despite the fact that sulphuric compounds in coffee beans is present only in minor quantities, they significantly affect the quality of coffee (Kim et al., 2018). The concentration of these compounds may vary depending on type of roasting. It has been observed that higher temperature promotes an increase in the content of sulphur compounds (Wei et al., 2017). At this point, for the quality, the balance of compounds is more important, than the highest concentration. For example, 2-furfurylthiol is known with pleasant roasted coffeelike aroma in low concentration (in light-medium roast coffees). At dark roast level, there are formed sulphuric compounds like 2-methyl-3-furanthiol (sulphury / vegetable flavour) and dimethyl disulphide (sulphury / cabbage flavour) from methanethiol oxidation (Kim et al., 2018; Mayer et al., 1999). Methanethiol increases with the roasting process till dark roast level, and then by oxidation process, it converts to dimethyl disulphide. The presence of this compound in coffee indicates the quality loss and could be considered as a quality marker (Poltronieri, Rossi, 2016).

By increasing roasting process time and temperature, the pleasant aroma, flavour compounds of pyrazines, aldehydes and ketones are imparting to bitter and harsh notes. Meanwhile, this transformation sets these compound groups as cup quality measurements. Specialty coffee sensory characteristics are associated with floral, fruity compound notes, which are found in the highest concentration in light-medium roast level if the roasting fluctuates in the range of $200-240{ }^{\circ} \mathrm{C}$ temperature.

Specialty coffees set higher goals towards sensory attributes, and specialty coffee standards help to exclude the damaged coffee defects before roasting and after the roasting process during storage.

\section{Conclusions}

Bioactive compounds like chlorogenic acid, trigonelline and caffeine have the highest value in light roasted coffee, while chlorogenic acid lactones and melanoidins are formed at light-medium roast level. The lightmedium roast level using range of $200-225^{\circ} \mathrm{C}$ ensures better preservation of phenolic compounds and therefore higher antioxidant activity. Specialty coffee aroma profile includes sweet, fruity flavour notes, which are developed in light-medium, medium roast level when temperature between $200-240{ }^{\circ} \mathrm{C}$ is applied. In conclusion, the profile and concentration of biologically active compounds in coffee beans mainly depends on the degree of roasting which in turn affects aroma and taste. Observing all the rules of coffee roasting, it is possible to maintain the quality and nutritional value of coffee.

\section{Acknowledgment}

The present research has been supported by the program 'Strengthening Research Capacity in the Latvia University of Life Sciences and Technologies' project 'The changes of biologically active compounds of Specialty coffee under the influence of technological processes' (Z22).

\section{References}

1. Alex M. de C., Juliana C. de R., Tiago T. R., Andre D. F., Ramiro M. R., Antonio N. G. M., Gladyston R. C. (2016) Relationship between the sensory attributes and the quality of coffee in different environments. African Journal of Agricultural Research, Vol. 11(38), p. 3607-3614.

2. Bartel, C., Mesias, M., Morales, F. J. (2015) Investigation on the extractability of melanoidins in portioned espresso coffee. Food Research International, Vol. 67, p. 356-365.

3. Bekedam E., Loots M., Schols H., Van Boekel M., Smit G. (2008) Roasting effects on formation mechanisms of coffee brew melanoidins. Journal of Agricultural and Food Chemistry, Vol. 56, p. 7138-7145. 
4. Bhumiratana N., Adhikari K., Chambers E. (2011) Evolution of sensory aroma attributes from coffee beans to brewed coffee. LWT-Food Science and Technology, Vol. 44(10), p. 2185-2192.

5. Bressanello D., Liberto E., Cordero C., Rubiolo P., Pellegrino G., Ruosi M. R., Bicchi C. (2017) Coffee aroma: Chemometric comparison of the chemical information provided by three different samplings combined with GC-MS to describe the sensory properties in cup. Food Chemistry, Vol. 214(Supplement C), p. 218-226.

6. Carlos R., Mercadante A., Machado-Faria A., Bragagnolo N. (2014) Roasting process affects the profile of diterpenes in coffee. European Food Research and Technology, Vol. 239(6), p. 961-970.

7. Carman A. J., Dacks P. A., Lane R. F., Shineman D. W., Fillit H. M. (2014) Current evidence for the use of coffee and caffeine to prevent age-related cognitive decline and Alzheimer's disease. Journal of Nutrition, Health and Aging, Vol. 18(4), p. 383-392.

8. Cheong M. W., Tong K. H., Ong J. J. M., Liu S. Q., Curran P., Yu B. (2013) Volatile composition and antioxidant capacity of Arabica coffee. Food Research International, Vol. 51(1), p. 388-396.

9. Coelho C., Ribeiro M., Cruz A. C. S., Domingues M.R.M., Coimbra M. A., Bunzel M., Nunes F. M. (2014) Nature of phenolic compounds in coffee melanoidins. Journal of Agricultural and Food Chemistry, 62(31), p. 7843-7853.

10. Donnet M. L., Weatherspoon D. D., Hoehn J. P. (2008) Price determinants in top-quality e-auctioned specialty coffees. Agricultural Economics, Vol. 38(3), p. 267-276.

11. Dorfner R., Ferge T., Kettrup A., Zimmermann R., Yeretzian C. (2003) Real-time monitoring of 4-vinylguaiacol, guaiacol, and phenol during coffee Roasting by resonant laser ionization time-of-flight mass spectrometry. Journal of Agricultural and Food Chemistry, Vol. 51, p. 5768-5773.

12. Farah A., Paulis T., Trugo L. C., Martin P. R. (2005) Effect of roasting on the formation of chlorogenic acid lactones in coffee. Journal of Agricultural and Food Chemistry, Vol. 53, p. 1505-1513.

13. Fassio L. O., Malta M. R., Liska G. R., Alvarenga S. T., Sousa M. M. M., Farias T. R. T., Pereira R. G. F. A. (2017) Sensory profile and chemical composition of specialty coffees from Matas de Minas Gerais, Brazil. Journal of Agricultural Science, Vol. 9(9), p. 78.

14. Frank O., Blumberg S., Kunert C., Zehentbauer G., Hofmann T. (2007) Structure determination and sensory analysis of bitter-tasting 4-vinylcatechol oligomers and their identification in roasted coffee by means of LC-MS / MS. Journal of Agricultural and Food Chemistry, Vol. 5, p. 1945-1954.

15. Gutiérrez-Grobe Y., Chávez-Tapia N., Sánchez-Valle V., Gavilanes-Espinar J., Ponciano-Rodríguez G., Uribe M., Méndez-Sánchez N. (2012) High coffee intake is associated with lower grade nonalcoholic fatty liver disease : The role of peripheral antioxidant activity. Annals of Hepatology, Vol. 11(3), p. 350-355.

16. Jeszka-Skowron M., Sentkowska A., Pyrzyńska K., De Peña M. P. (2016) Chlorogenic acids, caffeine content and antioxidant properties of green coffee extracts: Influence of green coffee bean preparation. European Food Research and Technology, Vol. 242(8), p. 1403-1409.

17. Keefe J. H. O., Bhatti S. K., Patil H. R., Dinicolantonio J. J., Harm P. D., Lucan S. C., Lavie C. J. (2013) Effects of habitual coffee consumption on cardiometabolic disease, cardiovascular health, and all-cause mortality. Journal of the American College of Cardiology, Vol. 62(12), p. 1043-1051.

18. Kim S.Y., Ko J.A., Kang B.S., Park H.J. (2018) Prediction of key aroma development in coffees roasted to different degrees by colorimetric sensor array. Food Chemistry, Vol. 240, p. 808-816.

19. Lopes G. R., Ferreira A.. S., Pinto M., Passos C. P., Coelho E., Rodrigues C., Figueira C., Rocha S. M, Fernando M. N., Coimbra M. A. (2016) Carbohydrate content, dietary fibre and melanoidins: Composition of espresso from single-dose coffee capsules, Food Research International, Vol.89(2016), p. 989-996.

20. Mancini R. S., Wang Y., Weaver D. F. (2018) Phenylindanes in brewed coffee inhibit amyloid-beta and tau aggregation. Frontiers in Neuroscience, Vol. 12(October), p. 1-14.

21. Duarte S. M. da S., Abreu C. M. P. de, Henezes H. C. de, Santos M. H. dos, Gouvea, C. M. C. P. (2005) Effect of processing and roasting on the antioxidant activity of coffee brews. Ciencia y Tecnología de Alimentos, Vol. 25(2), p. 387-393.

22. Martínez-Lopez S., Sarriá B., Mateos R., Bravo-Clemente L. (2018) Moderate consumption of a soluble green/ roasted coffee rich in caffeoylquinic acids reduces cardiovascular risk markers: results from a randomized, cross-over, controlled trial in healthy and hypercholesterolemic subjects. European Journal of Nutrition, Vol. 61, p. 1-14.

23. Mayer F., Czerny M., Grosch W. (1999) Influence of provenance and roast degree on the composition of potent odorants in Arabica coffees. European Food Research and Technology, Vol. 209, p. 242-250.

24. McCoy M. J., Hoppe Parr K. A., Anderson K. E., Cornish J., Haapala M., Greivell J. (2017) Diacetyl and 2,3-pentanedione in breathing zone and area air during large-scale commercial coffee roasting, blending and grinding processes. Toxicology Reports, Vol. 4, p. 113-122.

25. Mojica B. E., Fong L. E., Biju D., Muharram A., Davis I. M., Vela K. O., Rios D., Osorio-Camacena E., Kaur B., Rojas S.M., Forester S. C. (2018) The impact of the roast levels of coffee extracts on their potential anticancer activities. Journal of Food Science, Vol. 00(Nr. 0,2018), p. 1-6.

26. Moon J. K., Shibamoto T. (2009) Role of roasting conditions in the profile of volatile flavor chemicals formed from coffee beans. Journal of Agricultural and Food Chemistry, Vol. 57(13), p. 5823-5831.

27. Moreira A. S. P., Nunes F. M., Domingues M. R., Coimbra M. A. (2012) Coffee melanoidins: structures, mechanisms of formation and potential health impacts. Food \& Function, Vol. 3(9), p. 903.

28. Murkovic M., Bornik M. (2007) Formation of 5-hydroxymethyl-2-furfural (HMF) and 5-hydroxymethyl-2-furoic acid during roasting of coffee. Molecular Nutrition \& Food Research, Vol. 51(4), p. 390-394.

29. Nuhu A. A. (2014) Bioactive micronutrients in coffee: recent analytical approaches for characterization and quantification. ISRN Nutrition, Vol. 2014, p. 1-13.

30. Parenti A., Guerrini L., Masella P., Spinelli S., Calamai L., Spugnoli P. (2014) Comparison of espresso coffee brewing techniques. Journal of Food Engineering, Vol. 121(1), p. 112-117.

31. Piccino S., Boulanger R., Descroix F., Sing A. S. C. (2014) Aromatic composition and potent odorants of the "specialty coffee" brew "Bourbon Pointu" correlated to its 
three trade classifications. Food Research International, Vol. 61, p. 264-271.

32. Pilipczuk T., Kusznierewicz B. (2014) The influence of roasting and additional processing on the content of bioactive components in special purpose coffees. Journal of Food Science and Technology, Vol. 52(9), p. 5736-5744.

33. Poltronieri P., Rossi F. (2016) Challenges in Specialty coffee processing and quality assurance. Challenges, Vol 7(19), p. 1-22.

34. Ribeiro J. S., Augusto F., Ferreira M. M. C., Salva T. J. G. (2010) Uso de perfis cromatográficos de voláteis de cafés arábicas torrados para a diferenciação das amostras segundo o sabor o aroma e a qualidade global da bebida. Quimica Nova, Vol. 33(9), p. 1897-1904.

35. Specialty Coffee Association (2015) Cupping Specialty Coffee [accessed on 10.02.2019.] Available: http://www.scaa.org/PDF/resources/cuppingprotocols.pdf

36. Somporn C., Kamtuo A., Theerakulpisut P., Siriamornpun S. (2011) Effects of roasting degree on radical scavenging activity, phenolics and volatile compounds of Arabica coffee beans (Coffea arabica L. cv. Catimor). International Journal of Food Science and Technology, Vol. 46(11), p. 2287-2296.

37. Steen I., Waehrens S. S., Petersen M. A., Münchow M., Bredie W. L. P. (2017) Influence of serving temperature on flavour perception and release of Bourbon Caturra coffee. Food Chemistry, Vol. 219, p. 61-68.

38. Suslick B. A., Feng L., Suslick K. S. (2010). Discrimination of complex mixtures by a colorimetric sensor array: Coffee aromas. Analytical Chemistry, Vol. 82(5), p. 2067-2073.

39. Taguchi H., Sakaguchi M., Shimabayashi Y. (1985) Trigonelline content in coffee beans and the thermal conversion of trigonelline into nicotinic acid during the roasting of coffee beans Graecum L. (Fenugreek) from which the was found in coffee beans, amongthe various Assay for trigonelline After meth. Agricultural and Biological Chemistry, Vol. 49(12), p. 3467-3471.

40. Toledo P. R. A. B., Pezza L., Pezza H. R., Toci A. T. (2016) Relationship between the different aspects related to coffee quality and their volatile compounds. Comprehensive Reviews in Food Science and Food Safety, Vol. 15(4), p. 705-719.

41. Tolessa K., Rademaker M., De Baets B., Boeckx P. (2016) Prediction of specialty coffee cup quality based on near infrared spectra of green coffee beans. Talanta, Vol. 150, p. 367-374.

42. Velásquez S., Peña N., Carlos J., Gutierrez N., Sacks G. L. (2019) Volatile and sensory characterization of roast coffees - Effects of cherry maturity. Food Chemistry, Vol. 274, p. 137-145.

43. Vignoli J. A., Viegas M. C., Bassoli D. G., Benassi M. de T. (2014) Roasting process affects differently the bioactive compounds and the antioxidant activity of arabica and robusta coffees. Food Research International, Vol. 61, p. 279-285.

44. Wei L., Yu G., Wai M., Curran P., Yu B. (2017) Modulation of the volatile and non-volatile profiles of coffee fermented with Yarrowia lipolytica: II. Roasted coffee. LWT-Food Science and Technology, Vol. 80, p. 32-42.

45. Yang N., Liu C., Liu X., Degn T. K., Munchow M., Fisk I. (2016) Determination of volatile marker compounds of common coffee roast defects. Food Chemistry, Vol. 211, p. 206-214.

46. Yoshinari O., Igarashi, K. (2010) Anti-diabetic effect of trigonelline and nicotinic acid, on KK- $\mathrm{A}^{\mathrm{y}}$ Mice. Current Medicinal Chemistry, Vol. 17, p. 2196-2202. 